\title{
Study on the Application of Artistic Forms of Yangwuling Ceramics in Contemporary Ceramic Art
}

\author{
Shengqi Chen \\ The Department of Art and Design \\ Hunan City University \\ Yiyang, Hunan, China 413000
}

\begin{abstract}
Yangwuling Kiln takes the strengths of kiln-eyes from various regions in terms of ornamentation, glazing color, modeling and so on. Its unique artistic form not only enriches the ancient ceramic art, but also can be applied to the contemporary ceramic art, to enrich the form, technique and connotation of the modern ceramic art and create the solemn, elegant and plain artistic style, bringing new vitality and charm to the ceramic art.
\end{abstract}

Keywords-Yangwuling ceramics; artistic form; decoration; glazing color; modeling

\section{INTRODUCTION}

Yangwuling Kiln flourished in the Song and Yuan Dynasties, and declined in the late Ming Dynasty and early Qing Dynasty. In Song and Yuan Dynasties, Yangwuling Kiln took the strengths of kiln-eyes of various regions to make celadon, bluish white porcelain (also called shadowy blue glaze porcelain), white glazed porcelain, black glazed porcelain and sauce glazed porcelain. At the same time, it also imitated celeste blue glaze of Ru Kiln, glaze of Ge Kiln and plum green glaze of Longquan Kiln, and the brown color also appeared. Therefore, the study of Yiyang Yangwuling Kiln is the study of strengths of various kiln-eyes. The unique artistic forms of Yiyang Yangwuling Kiln in terms of ornamentation, glazing color, modeling and other aspects not only enrich the ancient ceramic art, but also can be applied to modern design, creating a solemn, elegant and plain artistic style, meeting people's retro feelings.

\section{UNIQUE ARTISTIC FORMS OF YANGWULING CERAMICS}

Yangwuling Kiln is located in the hilly land of Zaohe, Yangsipailou and Gaoling at the junction of Yangwuling Town and Shisun Town of Yiyang, Hunan. Its artistic forms are unique in style and rich in pattern. The porcelain varieties that have been made in it include white glaze, celadon glaze, and black glaze, shadow blue and bluish white. Vessel shapes include bowl, dish, cup, plate, small cup and lamp, and decorations are mostly brown dotted plum pattern and printed lotus pattern. The tire is white or gray, the glazing surface is gracked glaze, glazing color is of different shades, decorated with sauce-color decoration, carved flowers and underglaze painted lotus petals, black glaze device with cup, stem cup, and the tire is gray, with carved lotus petal decoration.

\section{A. Artistic Style of Yangwuling Ceramics' Ornamentation}

Yangwuling Kiln's ornamentation is not limited to landscape, flowers, birds, dragons, figures, etc., instead, its content fully reflects the cultural characteristics of the local lake area, with more sense of the times and regionality. Traditional ornamentations include algae, curly grass, chrysanthemum, bamboo, plum, orchid, flowers and birds, fish and insects, figures, landscapes, the "three cold-weather friends" -- pine, bamboo and plum, phoenix, and dragon and so on. The expression technique of text form, such as poetry, is also often used in combination with contemporary aesthetic concepts, writing poetry and other text ornamentations and auspicious words and Tangmingkuan, namely the names of halls and rooms as well as reign titles. Text ornamentations consist of blessings, emoluments, longevity and surnames. The auspicious words include $\mathrm{Fu} \mathrm{Ru}$ Dong Hai (happiness as immense as the Eastern Sea), Wo Zhi Fu Gui (my wealth and honor), Yi Jia He Qi Zi Sun Xian (a harmonious family has virtuous children), Wan Nian Xing Wang Fu Gui Chun (years of prosperity with prosperous spring) and so on. In addition, there are incised decorations, carved flowers, printed flowers and other production processes. In particular, the level of printing technology has achieved a very high standard, which can be compared with the printed porcelain produced by other famous kilns.

From the ornamentation content, the bluish white porcelain decorations of Yangwuling Kiln are quite unique with lively and bold painting as well as smooth strokes, which are vivid and natural, and mostly are relatively abstract, freehand, and simple, with strong random, rugged beauty, as well as obvious local characteristics and cultural connotations. The expression technique with surnames as ornamentations is also very rare among porcelains made in other kiln-eyes, which is the same as simple symbol of modern ceramic ornaments. It also absorbs the text decoration form of poetry used by Changsha Kiln in Tang Dynasty. For example, "Sleep in spring, unaware of dawning; Then hear birds sing everywhere", and the doggerel reflecting the folk culture of lake area. The ornamentation uniqueness is a main feature of Yiyang bluish white decoration. The difference between the ornamentation on Yiyang bluish white porcelains and that of other kiln-eyes is that it does not have a specific pattern, the pictures are painted arbitrarily, not limited to one type, one device has one 
style, having almost no similarities, some ornamentation are very rare, and their meaning is also very rich.

\section{B. Unique Charm of Glazing Color of Yangwuling Ceramics}

In the porcelains of Yangwuling Kiln in Song, Yuan and Ming dynasties, no styles of counting years have been discovered. Speculating according to the products, the upper limit of this Kiln is late Northern Song Dynasty or the early Southern Song Dynasty, the lower limit is late Ming Dynasty or early Qing Dynasty, with a burning period of up to 500-600 years. In Song and Yuan dynasties, kilns in Yiyang took the strengths of kiln-eyes of various regions to make celadon, bluish white porcelain (also called shadowy blue glaze porcelain), white glazed porcelain, black glazed porcelain and sauce glazed porcelain. At the same time, they also imitated celeste blue glaze of Ru Kiln, glaze of Ge Kiln and plum green glaze of Longquan Kiln. There are tens of kinds of porcelain glaze types with different colors.

The celadon, bluish white porcelain and other porcelains made by Yangwuling Kiln have well-glazed and smooth glazing surface, with strong glass texture, glittering and translucent glazing surface, looking like jade objects. The glazing surface of some utensils presents irregular small gracked glaze, with exquisite degree not inferior to the porcelain made by other kiln-eyes of Song and Yuan Periods.

The bluish white porcelain of Yangwuling Kiln is made using domestic cobalt material for color developing. The color appearance is divided into bright and gray. The bluish white tire body was heavy in early stages, and there are rust spots at the position with thick bluish white color. The glazing color of the bluish white porcelain is most between celeste, wintergreen and light greenish blue. Very few have the white glazing color, textures of glazing surface are fleshy and moisten, and some have flow glaze and exposed tire phenomenon.

\section{Features of Yangwuling Ceramics Modeling}

During the Song and Yuan Dynasties, the porcelains made by Yiyang Kiln have large quantity of types, specifications and varieties, large amount of output and good texture. However, in the Ming Dynasty, the types of utensils are relatively simple, which are generally confined to the tank, bowl, plate, pot, cover bowl, incense burner and other types. At the late Ming Dynasty or early Qing Dynasty, Yiyang kiln was impacted by Jingdezhen porcelain products and the river channel for transporting porcelains was blocked year by year, thus its production scale was getting smaller and smaller. The production scale of Yiyang kiln in Song and Yuan Dynasties was much larger than that in Ming Dynasty, with better product quality. Yiyang kiln flourished in the Song and Yuan Dynasties, and declined in the late Ming Dynasties.

The porcelain clay for making porcelains by Yangwuling Kiln is originated from the local bluish white and fine green crucible mud (commonly known as kaolin), so the tire body is mostly white and off-white, and there is a handful of grayyellow; with solid porcelain texture, dense and fine tire body, as well as good porcelain degree. The porcelain shape in Song and Yuan dynasties was quite structured. In the Ming Dynasty, the tire body was generally thick. Most of the objects were cut by sections, and at the belly of the porcelain appearance, cohesion traces can be seen obviously. Sense of concavoconvex at the position of interface can be felt when touching the inner wall of the porcelain. Moreover, the tire is not structured. Particularly, in the late Ming Dynasty, the surfaces of some objects were rough, which appear to be rough and irregular. The base of porcelain was generally thick, some had mastoid, with obvious rotation pattern.

The shapes of Yangwuling ceramics are mostly round wares, mainly for daily use. The shapes are simple, rich and plump, influenced by celadon of Song Dynasty. Most of the porcelains are bowls, plates, dishes and bottles. The shapes of bowl include bamboo hat-shaped bowl, bowing bowl, arc abdomen lip bowl, pier bowl, open mouth bowl, etc., rending the impression of natural and decent. Shapes of porcelain foot are also unique, with jade foot, cake feet, flat feet, lying feet and so on.

\section{APPLICATION OF TRADITIONAL ARTISTIC FORMS OF YANGWULING CERAMICS IN MODERN CERAMIC DESIGN}

With the improvement of people's living standard, the significant effect of aesthetic form has acted on people's values in terms of spirit. The modern ceramic design will also develop into an important factor influencing economic value along with this trend. Human create a colorful world with hands, but they also destroyed the natural colorful world they live in with their own hands. The alienation phenomenon generated by highly industrialized production makes people living in the city fear the machine indifference, and the shadow casted by high-rise buildings. People who live in such environment that lacks of humanity will feel they are getting farther and farther with the nature, with a sense of lossing nature. As a result, "return to nature" and retro become an important topic in modern design. Integrate elegance, magnificence, gorgeous colors into ceramic decoration, and make up the sense of losing nature with the natural implication, to achieve psychological balance, so that people feel the recovery of natural attributes. Apply the traditional ceramic artistic forms to modern design, to create a solemn, elegant, simple artistic style, thus to meet people's retro feelings.

Whether in the design form of traditional ceramics or the design inheritance of modern ceramics, color, quality and shape are three important factors, and color is the key factor of formal beauty of ceramic design. The ceramics of traditional art, such as underglaze color, red and green color, multicolored, pastel, blue and white, clashing color, etc. and the reason of different styles and abundant fun is the symbolic meaning of emotion granted to people by color has been grasped appropriately for creation, thus arouse people's awareness of aesthetic feeling, adding infinite connotation and mood to the works.

Glaze decoration is the most basic method of ceramic decoration. Colorful glazes not only meet the needs of people's daily lives, but also meet people's pursuit and enjoyment of ceramics beauty. The celadon, bluish white porcelain and other porcelains made by Yiyang kiln have well-glazed and smooth glazing surfaces with strong glass texture, crystal clear glazing surface, which are like jade objects, and the glazing surface of 
some utensils present to be small irregular gracked glaze. Its delicacy is no inferior to the porcelains made by other kilneyes of Song and Yuan Dynasties. In recent years, with the progress of science and technology, ceramic production technology is getting matured gradually, and decorative artists feel free to use color glaze. Give play to colored glaze in ceramic decoration, to show the artistic beauty of traditional ceramic culture spirit by taking full use of the changes of points, lines and surfaces, as well as the techniques, such as paste, heap, brush, dip, pick, print and spray. Science and technology is changing with each passing day, which also makes the use of modern ceramic integrated decorative glaze gradually be matured, giving full play to the potential advantage of color glaze, which has greatly promoted the development of ceramic decoration technology. When designing and making the modern furnishings porcelain and the porcelain for daily use, the glazing technology of modern polycrystalline fine powder dry glaze and the new process of electrostatic dry glazing technology can be used, to eliminate the drawbacks of traditional craft and modern process.

Traditional ceramic artistic form has been taken seriously in the design heritance of modern ceramics, especially the ornamentation and local kilns; all of them have a unique artistic form. Yangwuling Kiln takes the advantages of various kiln-eyes, forming a valuable cultural form and unique style with vivid and bold paintings, and most of them are abstract, freehand with randomness and rugged beauty, as well as higher artistic connotation, being pursued by the artistic circles, and even add the abstract elements, which are in line with modern requirements of the return to nature. The feature of ornamentation inherited from tradition is that it pays attention to the connotation of decoration. In modern ceramic design, in particular the porcelains for furnishing and daily use, the unique ornamentation and expression techniques of Yangwuling ceramics can be used by reference.

Traditional ceramics cover all aspects of life, and modern people need not only daily-use porcelain, but also the porcelain for furnishing and appreciation, as well as one which are practical and of artistic level. We combine the porcelain modeling with local folk kiln features with modern modeling, design according to use, use occasion, furnishings and displaying environment, and even can design according to the user gender, age and other factors. In the modern furnishing porcelain design, the production process of Yangwuling ceramics can be used by reference, porcelains for furnishing can even be made using wood kiln, and thus there will be kiln change and other unexpected effects, which is bound to be a good supplement to the modern ceramic design.

\section{CONCLUSION}

The development of society is characterized by diversification. The new trend of ceramic design is also developing toward the direction of diversification. The design of porcelain for daily is the product of the combination of life, science and art, with people's demand playing a leading role. While paying attention to modeling, materials and other factors, further refinement, research, analysis and prediction of people's psychology and hobbies shall be conducted in terms of color configuration, to reflect the spirit of the times, which is suitable for the needs of modern people. This is the inevitable result of the development of material civilization, but also the new topic placed in front of the designer. The application of Yiyang traditional ceramic artistic form to modern ceramic art design can enrich the form, technique and connotation of modern ceramic art design, and bring new vitality and charm to the ceramic art.

\section{REFERENCES}

[1] Li Na. On the Natural Beauty of Ceramic Art Design [J]. Ceramics, 2013 (09).

[2] Ren Yuan, Zhang Yue. Analysis of the Role of Traditional Pattern in Ceramic Design [J]. Art Science and Technology, 2015（07）.

[3] Wen Yang, Yu Qingchan. Analysis of the Contemporary Conversion of Traditional Ceramic Materials [J]. Art Panorama, 2013 (05)

[4] Tong Ling. Beauty in Form of Ceramic Art [J]. Popular Literature and Art, 2013 (07)

[5] Ge Yuechun. On the Inheritance and Innovation of Jun Ware Plastic Arts [J]. Jiangsu Ceramics, 2012（06）. 